\title{
Kidney transplant. Pan-American and Iberian productivity analysis in 2019 with a Mexican and chronic kidney disease perspective
}

\author{
Omar Sánchez-Ramírez*, Enrique M. Olivares-Durán² and Rubén Argüero-Sánchez ${ }^{1}$ \\ ${ }^{1}$ Department of Surgery, Faculty of Medicine, Universidad Nacional Autónoma de México, Mexico City; ${ }^{2} \mathrm{HE} 1$ Bajío High Specialty Medical Unit, \\ León National Medical Center, Instituto Mexicano del Seguro Social, León, Guanajuato. Mexico
}

\begin{abstract}
Background: Kidney transplant (KT) is the most common solid organ transplantation in the world. Objective: To analyze the information from Mexico on KT, waiting lists (WL) and patients on dialysis between 2012 and 2019 and compare that of 2019 with those of the countries of the American Continent, Spain and Portugal. Material and methods: The required information was obtained from the Global Observatory on Organ Donation and Transplantation (GODT). Results: Between 2012 and 2019, the annual number of kidney transplants (KTs) in Mexico increased by 12.5\%, while the WL by December 31 of each year did it by $86.1 \%$. In 2019, Spain and the US reported the highest KT rates, while Mexico ranked $8^{\text {th }}$ in the Pan-American and Iberian comparison, $6^{\text {th }}$ in the American Continent and $4^{\text {th }}$ in Latin America. Mexico did not report to GODT the number of patients on dialysis in 2019 and 2018. Conclusions: KTs should be considered an integral part of renal replacement therapies. The GODT reports include the numbers of patients on dialysis for each country. Mexico does not always report this data, probably due to the lack of a national registry of chronic kidney disease, the creation of which should be supported.
\end{abstract}

KEY WORDS: Kidney transplant. Waiting lists. End-stage renal disease. Dialysis. Renal replacement therapies. National registry of chronic kidney disease.

\section{Trasplante renal. Análisis de productividad panamericana e ibérica en 2019 con una perspectiva mexicana y de la enfermedad renal crónica}

\section{Resumen}

Antecedentes: El trasplante renal (TR) es el trasplante de órgano sólido más frecuente en el mundo. Objetivo: Analizar la información de México sobre TR, listas de espera (LE) y pacientes en diálisis entre 2012-2019 y comparar la del año 2019 con la de los países del continente americano, España y Portugal. Material y métodos: La información requerida se obtuvo del Global Observatory on Organ Donation and Transplantation (GODT). Resultados: Entre 2012-2019 en México el número anual de trasplantes renales (TR) se incrementó en un 12.5\%, mientras que la $L E$ al 31 de diciembre de cada año lo hizo en un 86.1\%. En 2019, España y EE.UU. reportaron las tasas más altas de TR, mientras que México ocupó el 8. lugar en la comparativa panamericana e ibérica, $6 .^{\circ}$ en el Continente Americano y $4 .^{\circ}$ en América Latina. México no reportó al GODT el número de pacientes en diálisis en 2019 y 2018. Conclusiones: Los TR deben considerarse parte integral de las terapias de reemplazo renal. Los reportes del GODT incluyen las cifras de pacientes en diálisis de cada país. México no siempre reporta este dato, probablemente por carecer de un registro nacional de enfermedad renal crónica, cuya creación debe apoyarse.

PALABRAS CLAVE: Trasplante renal. Listas de espera. Enfermedad renal crónica terminal. Diálisis. Terapias de reemplazo renal. Registro nacional de enfermedad renal crónica.c

\footnotetext{
Correspondencia:

Date of reception: 17-03-2021

*Omar Sánchez-Ramírez

Date of acceptance: 11-10-2021

E-mail: omarsanchez_ramirez@ hotmail.com

DOI: 10.24875/GMM.M21000620

Gac Med Mex. 2021;157:580-587

Contents available at PubMed license (http://creativecommons.org/licenses/by-nc-nd/4.0/).
} 


\section{Background}

Recently, the authors of this article published a document that analyzed organ donation and transplantation evolution and current state in Mexico over 12 years, from 2007 to $2018^{1}$. This article continues and expands that analysis with an emphasis on kidney transplantation (KT) as part of replacement therapies for end-stage renal disease (ESRD).

\section{Material and methods}

The 2019 information on KT from both living and deceased donors from the countries of the American continent, as well as that of Spain and Portugal, was collected and compared (a comparison hereinafter referred to as Pan-American and Iberian), including the figures corresponding to KT waiting lists, as well as the number of patients on a dialysis program for each country. In the case of Mexico, the same information was also collected for the 2012 to 2019 period, with the figures of the waiting lists for any solid organ (kidney, heart, liver, lung, pancreas and small intestine) on the same period being also added. To estimate the proportion the KTs carried out in 2019 represent with regard to the entire population on renal replacement therapy (RRT) at each country for that same year (with KT being included in that concept), the number of patients on dialysis by December 31 of that year had the number of KTs carried out in 2019 added, and then, the percentage the number of KTs represented with regard to that sum was calculated. Said percentage will be hereinafter abbreviated as [KT\%/RRT+KT].

Data sources were: a) The Global Observatory on Donation and Transplantation (GODT) ${ }^{2}$, and b) Newsletter Transplant annual publications, with the international figures on donation and transplantation recorded by the European Directorate for the Quality of Medicines \& Health Care of the Council of Europe $(E D Q M)^{3}$ jointly with the National Transplant Organization (ONT - Organización Nacional de Trasplantes) of Spain. Standardized figures per million population ( $\mathrm{pmp}$ ) were used. The number of authorized transplant centers by country was standardized per 10 million population in order to avoid that most data were only decimal figures. If any country of the American continent does not appear in any table or figure, it is because there was no data available in the databases consulted in 2019. Of the countries that have the geographical characteristic of being islands, only the information corresponding to Cuba and to the Dominican Republic was available.

\section{Results}

Figure 1 shows the proportion of patients waiting for a KT, with regard to the waiting list for all solid organs (kidney, liver, heart, lung, pancreas and small intestine) in Mexico between 2012 and 2019. Initially, it was $95 \%$, and it reached up to $97 \%$.

Figure 2 shows the dynamics of the KT waiting list between 2012 and 2019 in Mexico. Total number of patients registered as active on the waiting list during each year is compared (a figure that has already been calculated and recorded in the consulted databases and that is the result of adding to the number of patients on waiting list by 31 December of a given year the number of patients newly included in the waiting list during the following year ${ }^{3}$ ), as well as total number of KTs that were performed (transplants from living plus deceased donors), in addition to the number of patients who died or were withdrawn from the waiting list for various reasons, and finally, total number of patients who remained active on the waiting list by December 31 of each year. As for KTs annual number, this figure was 2,646 in 2012 and 2,976 in 2019 (an increase of $12.5 \%$ ). On the other hand, total annual number of active patients on the KT waiting list went from 12,291 patients in 2012 to 21,130 in 2019 (an increase of $71.9 \%$ ), while the number of patients who remained on the waiting list by December 31 of each year was 9,107 in 2012 and went to 16,947 in 2019 (an increase of $86.1 \%$ ).

If only patients who were newly admitted to the KT waiting list are considered for each year, figure 3 shows annual figures evolution between 2012 and 2019 , along with the evolution of the number of annually transplanted patients in Mexico. In said period, the number of patients who received a KT each one of those years never exceeded the number of patients who were newly admitted to the waiting list the same year.

Table 1 shows the population data for 2019, associated with data on the number of KT-authorized centers and the rate of KT per million population (pmp) for the countries of this Pan-American and Iberian comparison. The KT rate includes both living and deceased donor organs. Mexico exceeds by far all the countries included in this comparison, both in KT centers (273) absolute number, and in the rate of KT centers per 10 million population ( 20.6 centers $/ 10 \mathrm{mp}$ ). 


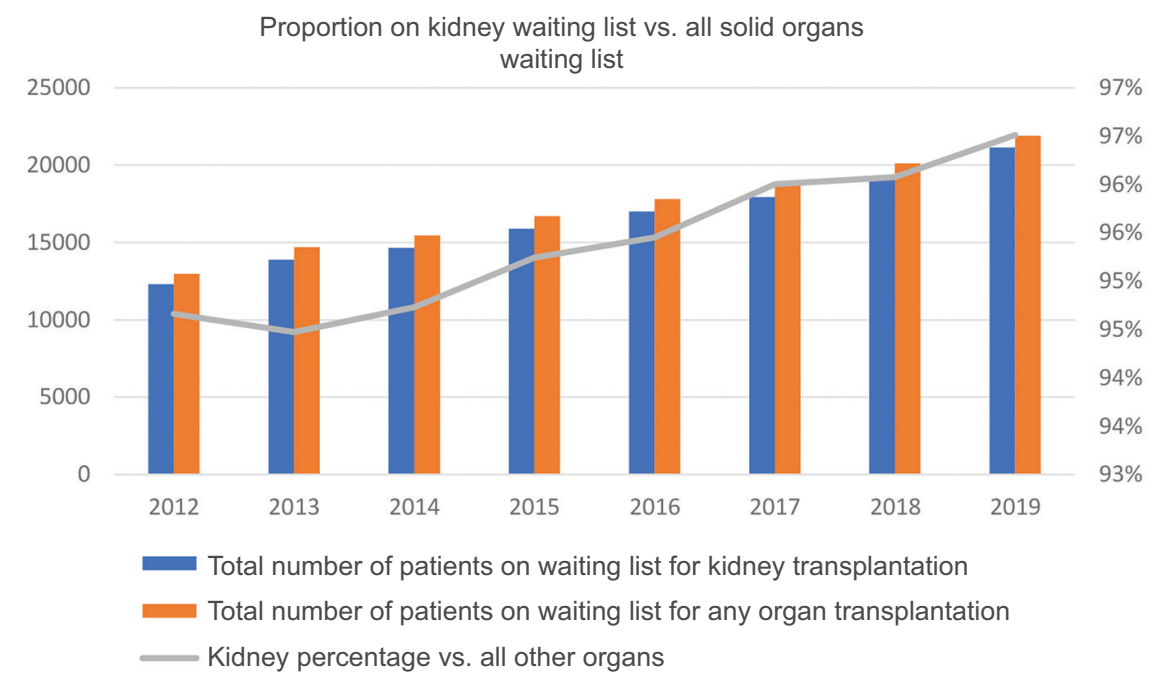

Figure 1. Percentage growth in the number of patients waiting for a kidney transplant vs. total number of patients waiting for a transplant of any other solid organ (kidney, liver, heart, lung, pancreas, small intestine) in the 2012-2019 period (created by the authors based on Global Observatory on Donation and Transplantation annual reports²).

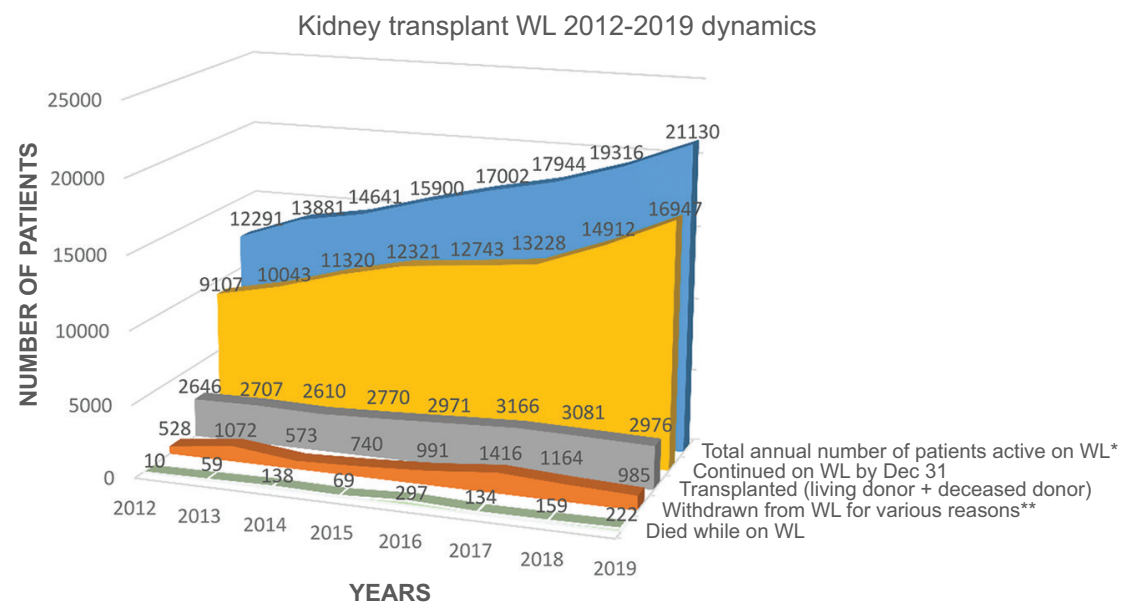

Figure 2. 2012-2019 figures, in Mexico, of total annual number of patients active on waiting list (WL) for kidney transplantation, compared with total number of performed kidney transplants (from living donor plus those from deceased donor), with the number of patients that each December 31 continued on waiting list. The patients who died while on WL during that year and those who were withdrawn from the WL for other (administrative) reasons are also shown (created by the authors based on Global Observatory on Donation and Transplantation annual reports ${ }^{2}$ ). ${ }^{*}$ Total annual number of active patients on WL appears in Global Observatory on Donation and Transplantation annual reports and is the result of the sum of the patients who remained on WL by December 31 of the year prior to the reported one plus the number of newly registered patients in the WL the year in question.

tVarious administrative reasons: loss of contact or follow-up, loss of health insurance coverage, change of place of residence, etc.

In this Pan-American and Iberian comparison, the number of authorized KT centers and their rate per 10 $\mathrm{mp}$ were not always directly related to productivity in terms of transplants, since, for example, Mexico, which leads in the rate of centers per $10 \mathrm{mp}$, had only the $8^{\text {th }}$ best $\mathrm{KT}$ rate $(22.5 \mathrm{pmp})$, while Spain and the US (both with a KT rate of $73.8 \mathrm{pmp}$, the highest in this comparison), ranked fifth and eleventh with regard to the rate of KT centers $/ 10 \mathrm{mp}$ (8.6 centers $/ 10 \mathrm{mp}$ and 7.0 centers $/ 10 \mathrm{mp}$, respectively). In addition, Chile, with 11.5 centers/10 mp (9 centers/10 mp less than Mexico), had a KT rate of $22.4 \mathrm{pmp}$ that year, almost identical to the Mexican rate $(22.5 \mathrm{pmp})$.

Table 2 shows the figures of KTs carried out in 2019 at the Pan-American and Iberian levels and the corresponding rates by country, both involving living and 


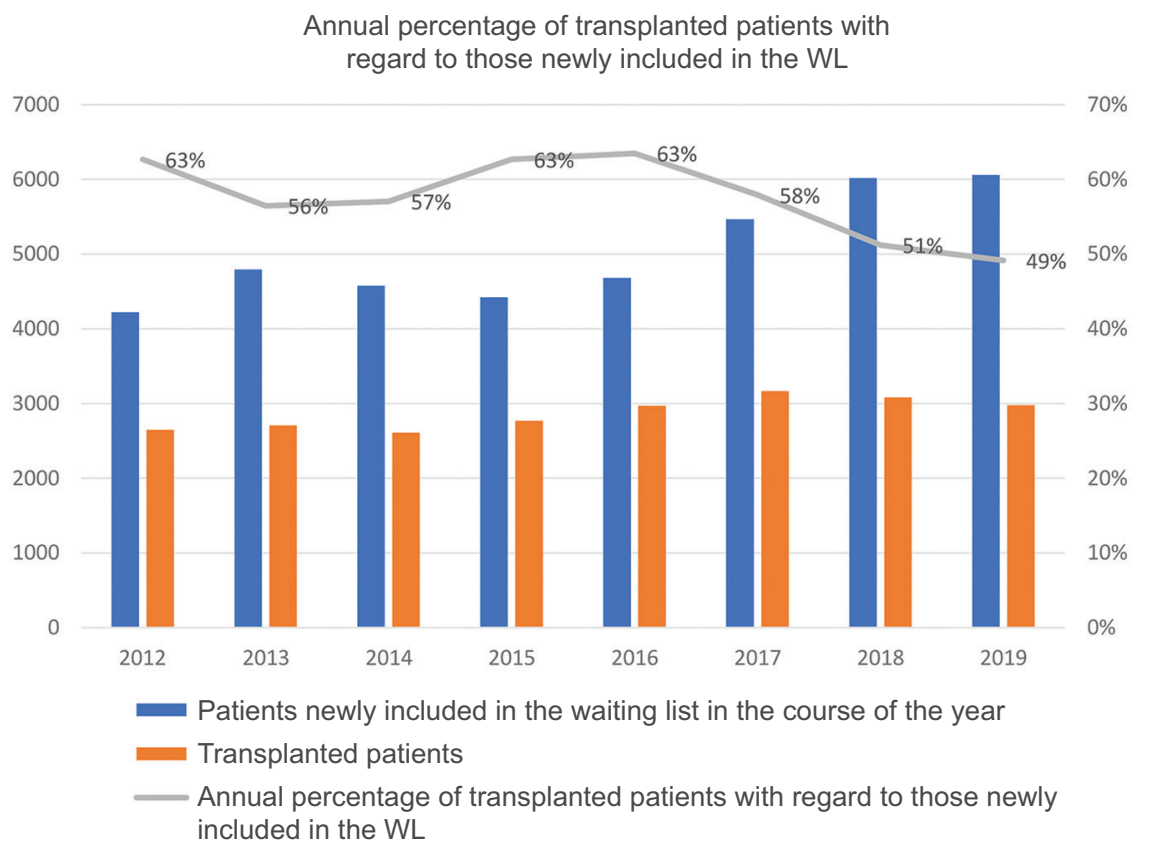

Figure 3. Number of patients newly included in the kidney transplant waiting list (WL) in the course of the year, in comparison with the number of kidney-transplanted patients on the same year, and percentage of transplanted patients with regard to those newly included in the WL (created by the authors based on Global Observatory on Donation and Transplantation annual reports ${ }^{2}$ for each year in the study period).

deceased donors. The number of patients on the waiting list for a KT by December 31 of that year are added, as well as the numbers of patients on any dialysis program for the same date. Total KT rate in Mexico of 22.5 pmp puts it at eighth place in this international comparison. This rate is largely explained $(68.9 \%)$ by a living donor transplant activity of $15.5 \mathrm{pmp}$. In turn, Spain and the US achieved the highest total KT rate in this comparison (73.8 pmp), but in both these countries, the largest number of KTs is explained by deceased donation: $90 \%$ in the case of Spain and $72 \%$ in the US. In this same parameter about KT percentage from cadaveric donors, Uruguay (87\%), Portugal (85\%), Brazil (83\%), Argentina (79\%) and Canada $(70 \%)$ also stand out, all of them with higher KT total rates than that of Mexico. Of the following five countries with lower KT total rates than Mexico in 2019, but $\geq 10.0$ pmp, except for Costa Rica, four generated most their KTs from deceased donors: Chile (76\%), Colombia (81\%), Cuba (87\%) and Ecuador (98\%). The remaining six countries had KT total rates lower than $10 \mathrm{pmp}$. Only five countries in this Pan-American and Iberian list had their highest proportions of KT from living donors: Venezuela (100\%), Guatemala $(94.5 \%)$, Mexico $(69 \%)$, Costa Rica (51\%) and the Dominican Republic (51\%).
When the number of patients who remained active on the kidney waiting list by December 31, 2019 was compared with the number of KTs that were performed in the course of that year at each country in this Pan-American and Iberian comparison, we found that, in Peru, Chile, Mexico and Panama, the ratio between both these figures represents around 5 or more times $(\geq 5: 1)$ the number of patients on waiting list with regard to the number of patients who underwent KT (Table 2). For Colombia, Argentina, Portugal and Brazil, this ratio is between $3: 1$ and 4:1. For Ecuador, Dominican Republic, USA and Uruguay, it is between 2:1 and 2.5:1. Paraguay and Cuba had a 1.5:1 ratio, and only Spain and Canada maintain a 1.1:1 ratio. The highest ratio occurred in Venezuela (140:1) and the best performance with regard to this ratio $(0.0 \%)$ was achieved by Costa Rica, which reported not having left any patient on the KT waiting list and performed $84 \mathrm{KTs}$ that year, with only 460 patients on dialysis by December 31, 2019.

Table 2 last column shows the figures of patients on any dialysis program. The data corresponding to 5 of the 19 countries included in this comparison (Portugal, Canada, Uruguay, Mexico and Guatemala) were not available in the databases that were consulted for this work. As described in the material and 
Table 1. Number of authorized kidney transplant centers by country, contrasted with the population and ordered according to the number of kidney transplant centers per ten million population. Data from the American continent plus Spain and Portugal

\begin{tabular}{|c|c|c|c|c|}
\hline Country & Population (pmi) & $\begin{array}{l}\text { Number of kidney } \\
\text { transplant centers }\end{array}$ & $\begin{array}{l}\text { Kidney transplant centers per } \\
\text { ten million population }\end{array}$ & $\begin{array}{c}\text { Kidney transplant rate } \\
\text { (pmp) }\end{array}$ \\
\hline Mexico & 132.3 & 273 & 20.6 & 22.5 \\
\hline Argentina & 45.1 & 59 & 13.1 & 37.1 \\
\hline Spain & 46.4 & 40 & 8.6 & 73.8 \\
\hline Chile & 18.3 & 21 & 11.5 & 22.4 \\
\hline Costa Rica & 5 & 5 & 10.0 & 16.8 \\
\hline Paraguay & 7 & 6 & 8.6 & 5.7 \\
\hline Uruguay & 3.5 & 3 & 8.6 & 44.3 \\
\hline Cuba & 11.5 & 9 & 7.8 & 17 \\
\hline Portugal & 10.3 & 8 & 7.8 & 49.9 \\
\hline Brazil & 212.4 & 153 & 7.2 & 29.7 \\
\hline USA & 329.1 & 232 & 7.0 & 73.8 \\
\hline Canada & 37.3 & 25 & 6.7 & 48 \\
\hline Colombia & 49.8 & 27 & 5.4 & 19 \\
\hline Panama & 4.2 & 2 & 4.8 & 7.4 \\
\hline Ecuador & 17.1 & 8 & 4.7 & 13.7 \\
\hline Dominican Rep. & 11 & 5 & 4.5 & 7.8 \\
\hline Peru & 32.9 & 12 & 3.6 & 5.7 \\
\hline Venezuela & 32.8 & 10 & 3.0 & 1.6 \\
\hline Guatemala & 17.6 & 4 & 2.3 & 6.2 \\
\hline
\end{tabular}

Adapted from European Directorate for the Quality of Medicines \& Health Care of the Council of Europe (EDQM) \& Organización Nacional de Trasplantes (ONT) ${ }^{\text {. }}$

methods section of this article, the percentage the number of KTs represented with regard to the total number of patients who at each country received some form of RRT, including KT [KT\%/RRT+KT], was estimated. The countries where this percentage was lower $(<3 \%)$ were Venezuela $(0.06 \%)$, Ecuador (1.44\%), Panama (1.45\%), Peru (1.46\%), Chile (1.63\%), Dominican Republic $(2.00 \%)$ and Paraguay $(2.60 \%)$. On the other hand, five countries had percentages $\geq 3.0 \%$ and $<10.0 \%$ : Colombia $(3.01 \%)$, USA (3.15\%), Cuba (5.25\%), Argentina (5.28\%) and Brazil (5.39\%). Only two countries in this comparison reached [KT\%/ RRT+KT] percentages $\geq 10 \%$ : Spain $(10.85 \%)$ and Costa Rica (15.44\%). The figures of patients on dialysis in Mexico were not reported in the databases consulted in 2019 or 2018 , but in 2017 they were 4 . That year, with the reported figures, the [KT\%/ $\mathrm{RRT}+\mathrm{KT}$ ] percentage was $1.66 \%(3,166 \mathrm{KTs}$ and 187,738 patients on dialysis).

\section{Discussion}

In a recent international study, when a large number of countries were compared, Mexico was found to have a high and growing chronic kidney disease (CKD) mortality rate, which is attributable, among other things, to insufficient access to RRT, combined with an increase in the prevalence of diabetes mellitus and hypertension ${ }^{5}$. This is consistent with reports from the Institute for Health Metrics and Evaluation regarding the place CKD has as a cause of death in our country ${ }^{6}$. This high prevalence of ESRD goes hand in hand with the fact that the most demanded organ for transplantation in Mexico is the kidney, and that it accounts for $97 \%$ with regard to all solid organs on waiting list. The problem is exacerbated by the fact that, in the period from 2012 to 2019, the number of patients who received a KT in Mexico was always lower than the 
Table 2. 2019 figures for the American continent plus Spain and Portugal regarding the number and rate per million population of kidney transplants performed in the year, and number of patients both on the waiting list and on a dialysis program by December 31 . Countries ordered by kidney transplant rate

\begin{tabular}{|c|c|c|c|c|c|c|c|c|}
\hline \multirow[t]{3}{*}{ Country } & \multicolumn{6}{|c|}{ Kidney transplant absolute numbers and rates } & \multirow{3}{*}{$\begin{array}{l}\text { Number of } \\
\text { patients } \\
\text { waiting list } \\
\text { Dec 31, } 2019\end{array}$} & \multirow{3}{*}{$\begin{array}{c}\text { Patients } \\
\text { on dialysis } \\
\text { by Dec } 31 \text {, } \\
2019\end{array}$} \\
\hline & \multicolumn{2}{|c|}{ From deceased donor } & \multicolumn{2}{|c|}{ From living donor } & \multirow{2}{*}{$\begin{array}{l}\text { KT total } \\
\text { number }\end{array}$} & \multirow{2}{*}{$\begin{array}{l}\text { Total } \\
\text { KT rate } \\
(\text { pmp) }\end{array}$} & & \\
\hline & $\begin{array}{c}\text { KT } \\
\text { number }\end{array}$ & $\begin{array}{l}\text { Deceased transplant } \\
\text { rate }(\mathrm{pmp})\end{array}$ & $\begin{array}{c}\text { KT } \\
\text { number }\end{array}$ & $\begin{array}{l}\text { Living transplant } \\
\text { rate (pmp) }\end{array}$ & & & & \\
\hline Spain & 3,088 & 66.6 & 335 & 7.2 & 3,423 & 73.8 & 3,933 & 28,138 \\
\hline USA & 17,406 & 52.9 & 6,867 & 20.9 & 24,273 & 73.8 & 60,566 & 746,557 \\
\hline Portugal & 439 & 42.6 & 75 & 7.3 & 514 & 49.9 & 2011 & nd \\
\hline Canada & 1,256 & 33.7 & 534 & 14.3 & 1,790 & 48 & 1,902 & nd \\
\hline Uruguay & 135 & 38.6 & 20 & 5.7 & 155 & 44.3 & 397 & nd \\
\hline Argentina & 1,324 & 29.4 & 351 & 7.8 & 1,675 & 37.1 & 5,218 & 30,054 \\
\hline Brazil & 5,227 & 24.6 & 1,071 & 5 & 6,298 & 29.7 & 25,146 & 110,445 \\
\hline Mexico & 926 & 7 & 2,050 & 15.5 & 2,976 & 22.5 & 16,947 & nd \\
\hline Chile & 311 & 17 & 99 & 5.4 & 410 & 22.4 & 2,113 & 24,800 \\
\hline Colombia & 768 & 15.4 & 179 & 3.6 & 947 & 19 & 2,822 & 30,507 \\
\hline Cuba & 170 & 14.8 & 25 & 2.2 & 195 & 17 & 300 & 3,520 \\
\hline Costa Rica & 41 & 8.2 & 43 & 8.6 & 84 & 16.8 & 0 & 460 \\
\hline Ecuador & 229 & 13.4 & 5 & 0.3 & 234 & 13.7 & 480 & 16,000 \\
\hline Dominican Rep. & 42 & 3.8 & 44 & 4 & 86 & 7.8 & 210 & 4,209 \\
\hline Panama & 19 & 4.5 & 12 & 2.9 & 31 & 7.4 & 230 & 2,109 \\
\hline Guatemala & 6 & 0.3 & 103 & 5.9 & 109 & 6.2 & nd & nd \\
\hline Peru & 137 & 4.2 & 52 & 1.6 & 189 & 5.7 & 940 & 12,773 \\
\hline Paraguay & 34 & 4.9 & 6 & 0.9 & 40 & 5.7 & 56 & 1,500 \\
\hline Venezuela & 0 & 0 & 6 & 1.6 & 6 & 1.6 & 843 & 10,300 \\
\hline
\end{tabular}

KT: kidney transplant; pmp: per million population; nd: no data.

Adapted from European Directorate for the Quality of Medicines \& Health Care of the Council of Europe (EDQM) \& Organización Nacional de Trasplantes (ONT)

number of patients who were newly registered on the waiting list at each one of those eight years.

However, the demand for KT reflected by the waiting list is incomplete, since in addition to the high prevalence of CKD, there is the problem of limited access to health care services in general, and to KT specifically. Said access is influenced by factors such as geographic barriers, non-affiliation to health institutions that offer dialysis and transplantation programs, socioeconomic barriers, lack of more highly committed and productive cadaveric organ donation and/or $\mathrm{KT}$ centers on one hand, and on the other, a large number of KT centers with minimal or almost no productivity ${ }^{1}$. In Mexico, it is necessary for public policies and quality programs that make equity in access to medical services and transplants a reality to be implemented. Accessibility, understood as "the possibility each individual has for making use of services when required" is, in the best-case scenario, the expression of universal coverage ${ }^{7}$.

But access to health services and, in the matter at hand, to dialysis and KT programs, should be intimately and inextricably related to quality: "quality in the abstract, without having access, is an absurdity, and access without quality is a lack of ethics"7. In this regard, it is surprising that Mexico has the highest number of KT centers per 10 million population in this Pan-American and Iberian comparison, in contrast to an insufficient productivity in KT from deceased donors, with a clear 2:1 
predominance of living donor transplantation, against the flow of international evidence that indicates lower costs of cadaveric donor KT and, especially, that the most successful KT programs with the best proportion of RRT at the expense of KT occur in countries with a high predominance of deceased donor transplantation ${ }^{8}$.

The inefficacy and inefficiency of the National Transplantation System of Mexico must be addressed not only from the traditional perspective of societal altruism in order for cadaveric donation of kidneys and other organs and tissues to be increased, but also from the perspective of governmental and institutional responsibility in order to plan, provide financial support and qualified human resources, and supervise a comprehensive reengineering program regarding the quality of the various sub-processes of organ and tissue donation and transplantation.

In addition, the lack of a Mexican CKD registry that includes all of the dialysis programs in the country not only hinders timely availability of reliable figures on the number of patients on dialysis each year, just as it occurred in 2019 and 2018 with Mexico's reports to the GODT, but also contributes to a poor quality of planning and results in CKD comprehensive care in Mexico. KT programs should be part of a national policy with a holistic approach that encompasses from CKD prevention to containment, as well as ESRD comprehensive treatment, where KT should be a clear therapeutic option early informed and proposed to all patients who suffer from it, simultaneously with the proposal of dialytic therapies, just as recommended by the International Society of Nephrology and the Transplantation Society. Recently, it has been suggested that a strategic goal for low- and middle-income countries should be that at least $20 \%$ of ESRD replacement therapies consist of $\mathrm{KT}$, something that has only been achieved in 12 countries with strong cadaveric donation programs ${ }^{8}$. Of the five countries with the best percentage achieved in this comparison, three are between 5 and 9\% (Cuba, Argentina and Brazil) and only two reached a proportion higher than 10\% (Spain and Costa Rica).

At the time this article was concluded (March 2021), the figures for donation and transplants in Mexico for the year 2020 were already available, provided by the National Transplant Center ${ }^{9}$. With 2020 having been the year of the coronavirus disease 2019 (COVID-19) pandemic, the most serious in 100 years, it is understandable that the figures reported for this year are low $(905 \mathrm{KTs}, 30.41 \%$ of the 2,976 KTs carried out in $2019^{3}$ ), but the progressive reactivation of the different programs is an exemplary sign of strength and resilience of the national transplant system and of the donation and transplant centers in Mexico and the world. A great solidary recognition to all those who dedicate themselves to this noble, fundamental and critical activity of modern medicine.

\section{Conclusions}

In order to fully evaluate the problem of kidney shortage for transplantation purposes, it is important for reliable figures of patients on dialysis programs to be included in all countries' national organ donation and transplantation systems annual reports. This is one of the many reasons why the creation of a CKD registry that accurately and reliably captures and reports this information is urgent in Mexico. In the approach to patients with CKD at advanced stages, an educational and informed consent process that integrates the option of KT as part of RRT for ESRD from the beginning is equally important. Finally, there are currents of academic thought in nephrology and KT that favor the concept of including a minimum percentage of $\mathrm{KT}$ into the goals of national transplantation systems as part of replacement therapies for ESRD.

\section{Funding}

This research has not received any specific grant from agencies of the public, commercial or non-profit sectors.

\section{Conflict of interests}

The authors declare that they have no conflicts of interest.

\section{Ethical disclosures}

Protection of human and animal subjects. The authors declare that no experiments were performed on humans or animals for this research.

Confidentiality of data. The authors declare that no patient data appear in this article.

Right to privacy and informed consent. The authors declare that no patient data appear in this article. 


\section{References}

1. Argüero-Sánchez R, Sánchez-Ramírez O, Olivares-Durán EM. Donación cadavérica y trasplantes de órganos en México. Análisis de 12 años y siete propuestas estratégicas. Cirugía y Cirujanos. 2020;88(3):254-62.

2. Global Observatory on Donation and Transplantation (GODT) [website] Gobierno de España, Ministerio de Sanidad [accessed: 21 August 2020]. Available at: http://www.transplant-observatory.org/

3. European Directorate for the Quality of Medicines \& Health Care of the Council of Europe (EDQM) \& Organización Nacional de Trasplantes (ONT). International Figures on Donation and Transplantation Activity. Year 2019. Newsletter Transplant EDQM. 2020;25:1-80.

4. European Directorate for the Quality of Medicines \& Health Care of the Council of Europe (EDQM) \& Organización Nacional de Trasplantes (ONT). International Figures on Donation and Transplantation Activity. Year 2017. Newsletter Transplant EDQM. 2018;23:1-81.
5. Global Burden of Disease, Injuries, and Risk Factors Study (GBD) Chronic Kidney Disease Collaboration. Global, regional, and national burden of chronic kidney disease, 1990-2017: a systematic analysis for the Global Burden of Disease Study 2017. Lancet. 2020;395:709-33.

6. Mexico [Internet]. Institute for Health Metrics and Evaluation (IHME) [accessed: 29 September 2020]. Available at: http://www.healthdata.org/ México

7. Fajardo-Dolci G, Gutiérrez JP, García-Saisó S. Acceso efectivo a los servicios de salud: operacionalizando la cobertura universal en salud. Salud Publica Mex. 2015;57:180-6.

8. O'Connell PJ, Brown M, Chan TM, Claure-del Granado R, Davies SJ, Eiam-Ong S, et al. The role of kidney transplantation as a component of integrated care for chronic kidney disease. Kidney Int Suppl. 2020;10:e78-e85.

9. Centro Nacional de Trasplantes. Reporte anual 2020 de donación y trasplantes en México. Centro Nacional de Trasplantes (CENATRA); January 2021 